\title{
PARA ALÉM DA PARTICIPAÇÃO: INTERFACES SOCIOESTATAIS NO GOVERNO FEDERAL
}

Roberto R. C. Pires e

Alexander C. N. Vaz

O Estado, no desempenho de suas funções e atividades, estabelece diversas e variadas formas de interação com cidadãos, empresas e atores sociais organizados e não organizados. Em regimes democráticos, tais interações tendem a ser ainda mais ampliadas, incidindo frequentemente sobre os processos decisórios relativos ao desenho de políticas e ao seu controle. No caso brasileiro, desde a Constituição de 1988, uma variedade de formas de interação entre órgãos do Poder Executivo e atores sociais diversos tem sido institucionalizada e mobilizada na produção de políticas públicas - indo desde fóruns públicos de participação e debate, como os conselhos, conferências e audiências públicas, a formas mais individualizadas ou mediadas por tecnologias de informação, como as ouvidorias e as consultas públicas, incluindo ainda reuniões, grupos de trabalho, mesas de negociação, comissões e comitês específicos envolvendo representantes do governo e da sociedade.

No entanto, a extensão dessa variedade de encontros entre Estado e sociedade e sua conformação na produção das políticas públicas têm sido raramente explorada. Em consequência, temos pouco conhecimento sobre as arquiteturas 
institucionais de interação já existentes (Vera e Lavalle, 2012), sobretudo suas diferenças de formatos, objetivos, papéis e aderência às burocracias estatais de distintas áreas. As análises sobre o tema, conduzidas nas últimas décadas, enfatizam algumas dessas formas de interação em detrimento de outras e, também, em detrimento de uma visão do seu conjunto. Se hoje já é possível identificarmos um acúmulo de estudos sobre orçamento participativo, conselhos e conferências, isso não se verifica no caso de audiências e consultas públicas, ouvidorias e outras formas de relação entre Estado e sociedade na gestão de políticas públicas. Ao não olharmos para o conjunto das possibilidades institucionais de interação, temos dificuldades de perceber suas inter-relações, diferenças, complementaridades ou tensões. Consequentemente, limitamos nossa compreensão sobre os processos de democratização do Estado brasileiro já em curso.

Este artigo se propõe ao duplo objetivo de: primeiro sugerir 62 lentes analíticas que deem conta de ampliar nossa percepção e capacidade de compreensão das possibilidades institucionais de interação entre Estado e sociedade na produção de políticas públicas no Brasil; e, segundo, a partir delas, mapear empiricamente as características desse fenômeno com foco na esfera federal. Desejamos compreender a extensão, a evolução temporal, a distribuição setorial e temática, além das implicações causadas pelos atuais formatos de interação entre atores estatais e atores sociais na gestão de políticas públicas. Quais são hoje as principais formas de interação entre Estado e sociedade existentes e em operação? Em que áreas têm sido mobilizadas com maior frequência e intensidade? De que formas vêm sendo usadas? E para quais propósitos têm-se direcionado?

Para abordar tais questões, o artigo está organizado da seguinte forma. Primeiro, fazemos uma breve recuperação da emergência de formas de participação da sociedade nos processos de formulação, implementação e controle de políticas públicas no Brasil, situando as abordagens teóricas 
que prevaleceram na sua análise e suas limitações em captar a variedade de formas de interação entre Estado e sociedade hoje existentes. Para lidar com essas limitações, revemos o conceito de "interface socioestatal" e discutimos como sua aplicação pode contribuir para ampliar nossa capacidade de explicação, com base em descrições mais precisas e completas que contribuam para uma melhor compreensão do fenômeno. Em seguida, apresentamos a estratégia metodológica, a fonte de dados empregada e os resultados do mapeamento das interfaces existentes nos programas e nos órgãos do governo federal no período de 2002 a 2010. Diferentemente de muitos estudos sobre o tema, os quais tendem a adotar como ponto de partida a observação do funcionamento e as repercussões dos próprios mecanismos de participação (como os conselhos, conferências etc.), nesta pesquisa voltamos nosso olhar para o universo dos programas federais que compõem os Planos Plurianuais (PPA) e, a partir deles, procuramos identificar a presença de formatos institucionais de interação Estado-sociedade. Com essa estratégia, obtemos uma leitura mais panorâmica e abrangente das formas pelas quais atores estatais se comunicam e se relacionam com atores sociais na gestão das ações de governo. Por fim, discutimos as principais conclusões do estudo, suas implicações para o debate teórico e apontamos algumas possíveis linhas de desenvolvimento de pesquisa sobre o tema.

\section{Formas de interação entre atores estatais e atores sociais na produção de políticas públicas}

Nos últimos 25 anos, foi marcante a expansão de formas de participação da sociedade nos processos de formulação, implementação e controle de políticas públicas, do nível local ao nacional (IBGE, 2009; Pires e Lopez, 2010; Avritzer, 2012). A emergência desse fenômeno suscitou produtivos debates no interior da teoria democrática. A observação do surgimento e funcionamento de procedimentos institucionais capazes de viabilizar a participação direta de cidadãos 
nos processos decisórios animou críticas às concepções "elitistas" de democracia (Santos e Avritzer, 2002) e abriu caminho para perspectivas teóricas que valorizaram o papel da sociedade civil, a constituição de espaços e fóruns coletivos e as possibilidades de deliberação pública (Habermas, 1996; Cohen e Arato, 1994; Avritzer, 1994; 2002; Dagnino, 2002).

Ainda que esse movimento tenha reconhecido que a

[...]participação abrange um universo diferenciado de manifestações empíricas, e [que] sempre haverá dificuldades na sistematização de todo seu repertório nas democracias contemporâneas (Avelar, 2007, p. 265),

a noção de participação é permeada pela ideia de "exercício coletivo do poder político" (Santos e Avritzer, 2002, p. 53).

Seja pela via teórica que enfatiza a deliberação pública ou por aquela que investiga a ação coletiva, as reflexões 64 desenvolvidas a respeito da participação tendem a ressaltar o caráter coletivo do processo.

Assim, se, por um lado, esses avanços contribuíram para a percepção de que a democracia pode e deve ser mais intensa, incorporando espaços de participação e deliberação pública aos tradicionais mecanismos de representação; por outro, ao privilegiarem o estudo de fóruns públicos e a atuação de atores sociais coletivos, restringiram o olhar de analistas a um subconjunto de formas de interação entre atores estatais e atores sociais. Isto é, passamos a compreender cada vez melhor a ocorrência de conselhos, orçamentos participativos e, mais recentemente, de conferências, e nos distanciamos cada vez mais da observação de outras formas de interação Estado-sociedade igualmente relevantes e cotidianas na gestão de políticas públicas, como reuniões entre grupos de interesse e atores governamentais, audiências e consultas públicas e ouvidorias, sem mencionar as formas não presenciais e virtuais mediadas por ferramentas de tecnologia de informação. 
A ênfase nos fóruns públicos de deliberação é fruto de concepções legítimas e muito bem fundamentadas, até pelos contextos histórico, político e intelectual em que emergiram as abordagens contra-hegemônicas de democracia. No entanto, quando se percebe o caminho que tomou o processo de redemocratização brasileiro, em particular com a emergência de novas instituições que incorporam o diálogo com a sociedade, é pertinente questionar se a lente analítica da participação e da deliberação não é por demais restritiva.

Em busca de uma perspectiva analítica que permita enxergarmos e avaliarmos as múltiplas e diversificadas ocorrências formais de interação entre Estado e sociedade na produção de políticas, recorremos ao conceito de "interfaces socioestatais", tal como desenvolvido por Vera (2006), Vera e Hevia (2006), Hevia e Vera (2010) e Lavalle e Vera (2010). A interface socioestatal consiste, segundo os autores, num espaço de interações de sujeitos individuais ou coletivos intencionados e portadores de projetos sociopolíticos específicos, marcado por relações (comumente) assimétricas de troca, disputa ou conflito em torno de algum tipo específico de bem, e cujos resultados podem gerar tanto implicações coletivas quanto implicações estritamente individuais. Ao considerarmos esses sujeitos, por um lado, estatais e, por outro, sociais, podemos pensar em arenas políticas cujas dinâmicas se delineiam por temáticas específicas e pelas preferências, narrativas e interesses de cada agente.

Tal noção resulta da combinação do conceito de interface, tal como proposto por Long (1999; 2004) em suas análises sobre a construção de conhecimento nas interações sociais ${ }^{1}$, com reflexões sobre a atuação do Estado (Roberts,

\footnotetext{
1 Para Long (2004), o conhecimento é uma construção cognitiva e social que tanto resulta quanto é moldado pelas experiências, ideias coincidentes e ideias divergentes que emergem nas interseções entre diferentes concepções de vida dos distintos atores. Vários tipos de conhecimento, como as opiniões formadas sobre
} 
2001). Assim, a noção de interface socioestatal chama a atenção para os encontros e as interações entre atores estatais e atores sociais e para o conhecimento ou conteúdo produzido nesses processos, deixando em aberto as características e os formatos dessa interação (sejam coletivos ou individuais), os procedimentos adotados e os resultados produzidos (seja negociação, decisão, expressão de conflito ou troca de informações). Dadas essas amplitudes, a noção de interface socioestatal tem o potencial de abarcar múltiplas e variadas arquiteturas institucionais para os encontros entre atores estatais e atores sociais na produção de políticas públicas (Vera e Lavalle, 2012).

O conceito de interface socioestatal pode ainda conter delimitações referentes a finalidades das formas de interações, podendo variar da simples consulta à corresponsabilização, ou cogestão de políticas. De acordo com Lavalle e Vera (2010), no primeiro caso, temos o subgrupo das interfaces 66 cognitivas, que reclamam um caráter mais comunicacional em relação ao Estado. Podem se subdividir em: interface de contribuição, na qual a sociedade informa ao Estado suas sugestões e/ou demandas; interface de transparência, na qual o Estado informa à sociedade suas perspectivas e ações; e interface comunicativa, na qual ambos os atores se informam mutuamente. No segundo caso, temos as interfaces políticas, mais associadas à condução das políticas, as quais comportariam: interface mandatória, na qual a sociedade é a dirigente do Estado; interface de transferência, na qual o Estado tem poder de controle sobre a sociedade; e interface

determinado indivíduo, sobre um contexto social, ou mesmo sobre instituições sociais, são importantes para a compreensão das interfaces sociais. $O$ conhecimento está presente em todas as situações sociais e em geral se associa fortemente com relações de poder, relativas à distribuição de recursos determinados. Em situações de intervenção política, por exemplo, o conceito assume especial relevância em função das diferenciações que tendem a emergir entre, por um lado, o conhecimento especializado e, por outro, o conhecimento "comum", referente àqueles indivíduos que não estudaram ou já trataram sistematicamente do assunto em pauta. 
de cogestão, na qual os processos decisórios são compartilhados entre ambos os atores.

Em síntese, a noção de interfaces socioestatais se situa menos como uma crítica às abordagens anteriores e mais como um alargamento de seu escopo analítico para dar conta da amplitude que o fenômeno empírico das relações entre Estado e sociedade no Brasil tem tomado. Esse alargamento segue duas direções: a) na percepção e consideração de uma diversidade ampla de formas de interações entre sujeitos sociais e sujeitos estatais - de fóruns públicos e espaços coletivizados voltados para a tomada de decisão, tal como enfatizado pelas abordagens deliberacionistas, a arenas de acesso restrito ou de contatos individualizantes, que envolvam apenas troca de informações, transparência e explicitação de conflitos; e b) na direção do reconhecimento de que envolvem o encontro de perspectivas distintas sobre os sentidos e os usos dessas interfaces, sendo no mínimo aquelas dos sujeitos sociais e dos atores do aparelho do próprio Estado. Se, por um lado, as perspectivas dos atores sociais sobre esses encontros têm tido maior presença na literatura especializada (principalmente naquela com foco na sociedade civil e nos movimentos sociais), por outro, as perspectivas dos atores estatais, seus repertórios, suas práticas e seus conhecimentos ainda permanecem subconsiderados no debate. É com base nessas duas frentes de interpretação que analisaremos as relações entre Estado e sociedade nos programas federais brasileiros.

\section{As interfaces socioestatais nos programas do governo federal}

Com o objetivo de compreender a extensão, a evolução temporal, a distribuição setorial e temática e as implicações causadas pelas atuais formas de interação entre atores estatais e atores sociais na gestão dos programas federais, adotou-se o banco de dados produzido pelo Instituto de 
Pesquisa Econômica Aplicada (Ipea) com base em informações obtidas no Sistema de Informações Gerenciais e de Planejamento (Sigplan), mantido pelo Ministério do Planejamento, Orçamento e Gestão (MPOG) ${ }^{2}$ como ferramenta de avaliação e acompanhamento dos programas integrantes dos Planos Plurianuais (Pires e Vaz, 2012).

O banco de dados consolidou as informações relativas à avaliação e ao acompanhamento de todos os programas federais para o período de 2002 a $2010^{3}$, incluindo nome e código do programa, órgão gestor (ministério, secretaria, autarquia etc.) ao qual pertence, grau de desempenho na consecução de metas e existência de formas de interação entre atores estatais e sociais em sua formulação, gestão e controle. Para cada tipo de interface indicada, obtivemos também explicações textuais, fornecidas pelos gerentes de cada programa, sobre sua forma de utilização, propósito e contribuições para os resultados obtidos.

Uma vez organizadas, as informações reunidas propiciaram um conjunto de análises estatísticas, de cunho tanto descritivo quanto inferencial. Os resultados das análises permitiram visualizar um panorama amplo das interfaces socioestatais nos programas federais em quatro dimensões, envolvendo: a) a identificação das variações nas formas e nos tipos de interação entre Estado e Sociedade existentes; b) a evolução ao longo do tempo da incidência e adoção de interfaces socioestatais; c) a distribuição das formas de interfaces socioestatais por áreas temáticas de políticas

2 O Sigplan foi criado em 2000 com o objetivo de auxiliar na elaboração e acompanhamento do Plano Plurianual (PPA), por meio da centralização e sistematização de informações quantitativas e qualitativas relativas à concepção, implementação e avaliação dos programas e ações do governo federal.

3 Este constitui o período para o qual foram disponibilizadas as informações em meio eletrônico. Em 2011, o sistema entrou em fase de extinção, sendo descontinuado em 2012 pelo MPOG. Informações relativas a períodos anteriores estavam disponíveis somente em arquivos físicos e em relatórios impressos. A organização e sistematização destas informações não se mostraram tarefas viáveis, tendo em vista o escopo e as possibilidades da presente análise. 
públicas; e, por fim, d) a avaliação das percepções dos gestores sobre as funções e as contribuições das interfaces na gestão dos programas. As quatro subseções que seguem expõem os resultados e as interpretações construídas baseadas em cada uma dessas dimensões.

\section{Tipos e formas de interface socioestatal}

A análise dos dados sobre os programas federais indicou variações importantes no que diz respeito às formas de interação entre atores estatais e atores sociais existentes para o período 2002-2010. Foi possível identificar sete tipos de interface socioestatal presentes nos programas do governo.

\section{Quadro 1}

Tipos e formas de interface socioestatal nos programas federais

\begin{tabular}{|c|c|}
\hline Tipo & Formas de interação \\
\hline Conselho & $\begin{array}{l}\text { Programa (ou seus subcomponentes) submetido } \\
\text { a discussões em algum conselho nacional }\end{array}$ \\
\hline Conferência & $\begin{array}{l}\text { Programa (ou seus subcomponentes) submetido } \\
\text { a discussões em alguma conferência nacional }\end{array}$ \\
\hline Consulta pública & $\begin{array}{l}\text { Programa (ou seus subcomponentes) envolvendo algum } \\
\text { processo de consulta pública sobre aspectos de seu } \\
\text { funcionamento, normatização etc. }\end{array}$ \\
\hline Audiência pública & $\begin{array}{l}\text { Programa (ou seus subcomponentes) envolvendo } \\
\text { algum processo de audiência pública sobre suas ações, } \\
\text { intervenções, iniciativas etc. }\end{array}$ \\
\hline Ouvidoria & $\begin{array}{l}\text { Atuação de ouvidoria, vinculada a algum órgão } \\
\text { (do próprio setor ou não), incidindo sobre programa - canalização } \\
\text { de denúncias, reclamações, críticas, sugestões etc. }\end{array}$ \\
\hline $\begin{array}{l}\text { Reunião com grupos } \\
\text { de interesse }\end{array}$ & $\begin{array}{l}\text { Reuniões entre associações civis, empresariais, sindicais, ou } \\
\text { movimentos sociais e órgãos ou representantes governamentais; } \\
\text { mesas de diálogos, fóruns, grupos de trabalho e outras formas de } \\
\text { interação pouco institucionalizadas que incidem sobre aspectos } \\
\text { da gestão de programas (conteúdos, metas, formas } \\
\text { de implementação, avaliação etc.) }\end{array}$ \\
\hline Outros & $\begin{array}{l}\text { Sítios de internet, telefones disponibilizados (SAC, disque } \\
\text { denúncia etc.), bem como ações pontuais com o objetivo } \\
\text { de divulgar aspectos de programas. }\end{array}$ \\
\hline
\end{tabular}

Fonte: Elaboração própria com base em dados do Sigplan (2010). 
Observa-se que as interfaces socioestatais se materializam nos programas do governo sob um leque de formatos e estruturas institucionais que não se restringem aos tipos que usualmente chamam mais a atenção dos pesquisadores e estudiosos da área, como os conselhos e as conferências. Uma análise comparativa desses formatos expressa suas principais diferenças em três eixos de variação: graus de institucionalização; tipos de inclusão do ator social (individual ou coletivizado); e regularidade dos encontros entre atores estatais e sociais.

Com relação ao grau de institucionalização, podemos perceber que as interfaces socioestatais existentes nos programas federais incluem desde formas de interação relativamente bem institucionalizadas a formas pouco formalizadas, no que tange à sua sustentação legal e funcionamento. No primeiro grupo, os conselhos e as conferências, além das ouvidorias, das audiências e das consultas públicas, destacam-se como interfaces que, em geral, são amparadas por atos normativos e legislação específica, 70 regulando sua existência, funcionamento, composição, procedimentos internos e decisórios. O segundo grupo, no qual se enquadrariam as reuniões com grupos de interesses, sítios de internet e serviços de atendimento telefônico, seria caracterizado por níveis de formalização menores, uma vez que seriam raros os casos em que essas interfaces teriam embasamento legal sólido, ficando seu funcionamento e operação mais sujeitos à discricionariedade da administração pública.

No que se refere ao tipo de inclusão por interface, percebe-se que esse varia em um contínuo que vai da interação entre agentes estatais e cidadãos individuais às interações que privilegiam a participação de atores coletivos (associações civis, ONGs, movimentos sociais etc.). Por fim, no que concerne à regularidade da interação, há tanto interfaces de caráter permanente ou que mobilizem cidadãos ou grupos sociais em intervalos estáveis de tempo, quanto interfaces de natureza mais episódica, ou criadas com objetivos específicos, os quais, quando atingidos, fazem que sua operação seja concluída ou descontinuada. 
Considerando-se essas duas últimas dimensões de variação (tipo de inclusão e regularidade), faz-se interessante ilustrar (Gráfico 1), ainda que de forma imprecisa, as semelhanças e diferenças entre as interfaces socioestatais existentes nos programas federais. $\mathrm{O}$ posicionamento de cada interface, ao longo dos dois eixos, se baseia em interpretações sobre as características gerais de seu funcionamento.

\section{Gráfico 1}

Tipos e formas de interface socioestatal nos programas federais

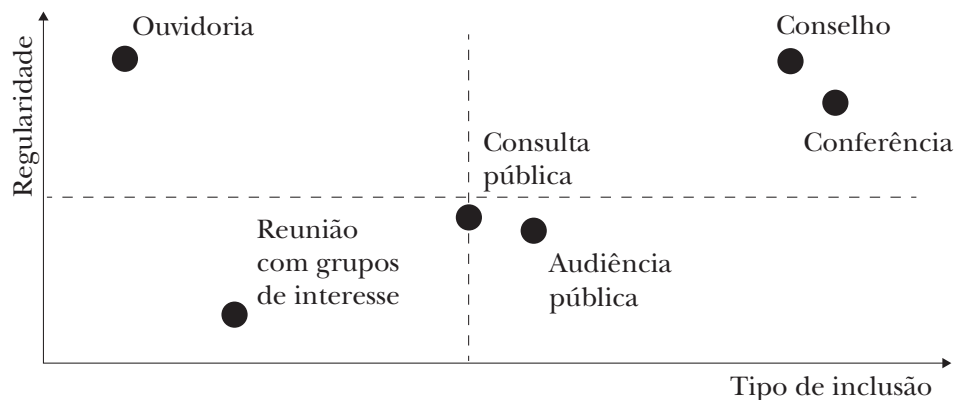

Fonte: Elaboração própria com base em dados do Sigplan (2010).

O Gráfico 1 contribui para a percepção de que os programas federais da última década têm sido submetidos a uma variedade de desenhos e formatos para interação Estado-sociedade. Por um lado, interfaces como conselhos, conferências, consultas e audiências públicas (lado direito da Gráfico 1) caracterizam-se por viabilizar fóruns públicos de discussão, ou espaços abertos de encontro entre atores estatais e atores sociais que tendem a representar interesses coletivos (ou participam nos espaços de forma a representar grupos, instituições, movimentos, causas etc.) Por outro, observam-se também interfaces que propiciam encontros entre cidadãos individuais e organizações estatais, como no caso das ouvidorias, ou fóruns de natureza restrita a um ou poucos grupos sociais ou econômicos selecionados, como as reuniões com grupos de interesse (lado esquerdo). 
Quando observamos o posicionamento das interfaces no que tange à sua regularidade, percebemos que enquanto conselhos, conferências e ouvidorias (porção superior) tendem a oferecer oportunidades de interação com maior regularidade - no caso de conselhos e conferências com reuniões periódicas e no de ouvidorias com abertura permanente ao contato com o cidadão -, as reuniões com grupos de interesse, consultas e audiências públicas (porção inferior), por sua vez, tendem a se fazer presentes de forma $a d$ hoc, isto é, são mobilizadas em resposta a mudanças no contexto político-administrativo (crises, ou fases de implementação de políticas públicas etc.) a partir da discricionariedade dos agentes governamentais e, assim, revelando menor regularidade em sua operação.

\section{Evolução temporal e incidência das interfaces socioestatais}

Com o objetivo de averiguar a mobilização dos distintos

72 formatos de interfaces socioestatais nas ações do governo federal ao longo da última década, produzimos duas séries de dados: uma indicando a quantidade de programas que declaravam ter pelo menos uma das sete formas de interação já descritas (seja apenas a realização de reuniões com atores selecionados, seja apenas a discussão de algum aspecto do programa em um conselho, seja, ainda, alguma combinação das interfaces identificadas); outra indicando a quantidade de órgãos - ministérios e outros órgãos da administração indireta a eles vinculados - que declararam ter pelo menos um programa com interfaces socioestatais.

Podemos observar no Gráfico 2 que, além do aumento do número de programas que primavam pela abertura de interfaces socioestatais, que passou de $81 \%$, em 2002, para 92,1\%, em 2010, houve também aumento na diversificação de ministérios e outros órgãos (fundações, autarquias, agências etc.), que passaram a interagir com atores sociais. Os dados apontam que, em 2002, 60,4\% dos órgãos tinham programas com 
pelo menos uma forma de interface socioestatal. Já em 2010, esse percentual atingiu 89,3\% dos órgãos federais. Assim, em 2010 observamos não apenas maior percentual de programas que adotam interfaces, mas, também, maior abrangência dos órgãos federais que conduzem seus programas dessa maneira.

\section{Gráfico 2}

Percentual anual de programas e órgãos com interface socioestatal

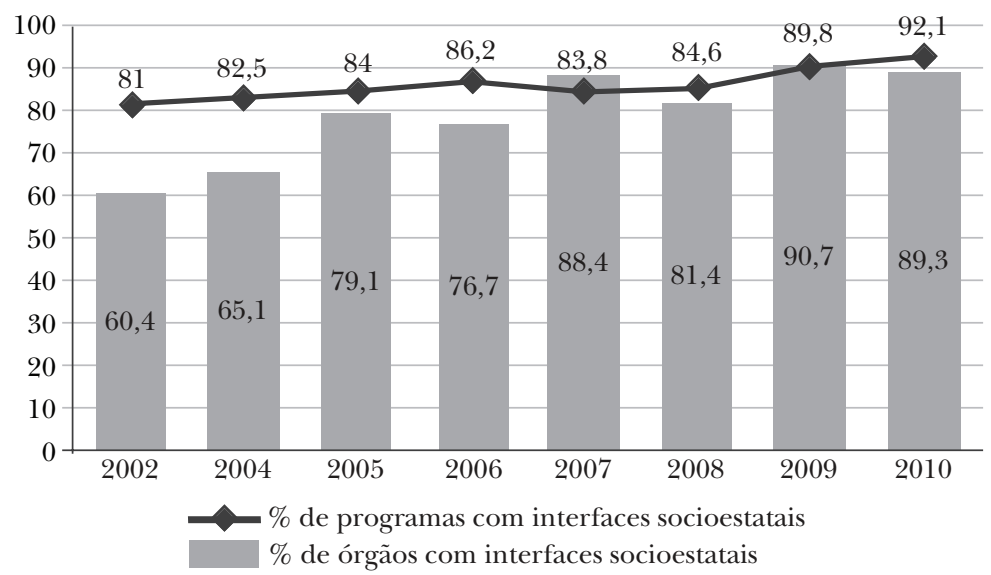

Fonte: Elaboração própria com base em dados do Sigplan (2010).

Apenas para ilustrar como essa abrangência de maior número de órgãos é ponto relevante, apresentamos alguns exemplos de áreas importantes nas quais se observaram interfaces socioestatais em 2010, mas que não estavam presentes em 2002. Em especial, vale notar a expansão desses mecanismos para órgãos ligados a outros poderes da república, como o Legislativo e o Judiciário. Por um lado, no caso do primeiro, é possível notar a presença tanto da Câmara dos Deputados quanto do Senado Federal como órgãos que não desenvolviam interfaces socioestatais em seus programas no ano de 2002, mas, em 2010, já declararam fazê-lo. Por outro, se olharmos o Judiciário, não é difícil perceber que a interação com a sociedade parece ter-se tornado ponto relevante para seus órgãos. É 
válido citar, por exemplo, que em 2002 órgãos como a Justiça Federal, a Justiça do Trabalho, a Justiça Eleitoral, o Ministério Público, o Supremo Tribunal de Justiça (STJ) e o Supremo Tribunal Federal (STF) não possuíam qualquer programa que incentivasse a adoção de interface socioestatal. Situação que já muda em 2010, pois todos esses órgãos declararam ter implementado em seus respectivos programas tais mecanismos (vale citar os exemplos das audiências públicas no STF).

Outro fator relevante quanto à incidência geral de interfaces socioestatais consiste no incremento do número médio de interfaces socioestatais nos programas de órgãos que já adotavam esses mecanismos desde 2002. Conforme aponta a Tabela 1, vemos que, em 2002, 11,5\% dos órgãos tinham até $25 \%$ de programas com interfaces e que, em 2010, todos os órgãos tinham pelo menos $25 \%$ de programas com interfaces. Nessa mesma linha, em 2002, 11,5\% dos órgãos tinham mais de $75 \%$ de seus programas com interfaces socioestatais, percen74 tual que sobe para $75,4 \%$, em 2010. O que esses percentuais deixam claro é que, além de um aumento geral do número de programas com interfaces socioestatais entre 2002 e 2010, houve, também, aumento da média de programas por órgão com desenvolvimento dessas interfaces. Esse aumento parece indicar que a maior parte dos órgãos passou, em 2010, a adotar interfaces socioestatais na maioria de seus programas e ações.

\section{Tabela 1}

Percentual geral e por órgão de programas com interface socioestatal

\begin{tabular}{|c|c|c|c|}
\cline { 3 - 4 } \multicolumn{2}{c|}{} & 2002 & 2010 \\
\hline \multirow{3}{*}{ Geral } & Até $25 \%$ & 80,7 & 92,1 \\
\hline \multirow{3}{*}{ Por órgão } & 11,5 & 0,0 \\
\cline { 2 - 4 } & De 25\% a 50\% & 46,2 & 2,9 \\
\cline { 2 - 4 } & De 50\% a 75\% & 30,8 & 21,7 \\
\cline { 2 - 4 } & Mais de 75\% & 11,5 & 75,4 \\
\cline { 2 - 4 } & Total & 100,0 & 100,0 \\
\hline
\end{tabular}

Fonte: Elaboração própria com base em dados do Sigplan (2010). 
Outra forma de se avaliar a evolução e a incidência de interfaces socioestatais nos programas federais é pela avaliação da utilização de cada uma das interfaces em relação umas com as outras. Isto é, quando observamos o conjunto de programas desenvolvidos pelo governo federal, é possível dizermos que há concentração em algum tipo específico de interface? Ou todas as variedades de interfaces estão sendo mobilizadas nos diferentes programas ao longo do tempo? O Gráfico 3 fornece alguns indícios a esse respeito. Como é possível observar, no período de 2002-2010, todas as modalidades de interfaces estão sendo mobilizadas a cada ano. Assim, não podemos falar que esteja em curso um processo de concentração ou hegemonização de um tipo de interface em relação aos outros. Apesar das variações nos percentuais relativos ano a ano não serem muito grandes, o teste qui-quadrado, tanto em relação à aderência em cada ano da amostra quanto em relação à homogeneidade em anos diferentes, fornece evidências suficientes para afirmarmos que tais diferenças são estatisticamente significativas ${ }^{4}$.

Ainda assim, é possível visualizarmos algumas tendências gerais na evolução da composição global do "estoque" de interfaces mobilizadas nos programas federais. Por um lado, percebe-se redução gradual da parcela ocupada pela categoria "outros", o que não necessariamente indica redução do número de interfaces nessa categoria (sítios de internet, SACs, disque denúncia etc.), mas apenas redução da participação desse

\footnotetext{
4 De 2002 a 2010, o valor do teste qui-quadrado $\left(\mathrm{Chi}^{2}\right)$ diminui consideravelmente, ainda que sempre se mantendo significativo a um nível de confiança de $95 \%$, dado que o valor mais extremo é o de 2010, com valor da estatística P em 0,0388. Em 2002, por exemplo, o teste retornou a um valor total de 32,5, o qual variou ao longo dos anos, passando por 18,87 em 2005, 17,7 em 2007 e, finalmente, 11,2 em 2010. Esse movimento implica considerar que o grau de variância da amostra para cada ano tendeu a diminuir consideravelmente, isto é, valores menores de qui-quadrado implicam maior probabilidade de aceitar a hipótese de que as variações de percentuais para cada ano não são significativas. Isso quer dizer, em última instância, que há evidências suficientes para sustentar a afirmativa de que, ao longo dos anos, os percentuais tendem à maior homogeneização, isto é, à maior semelhança, sugerindo que deixa de haver concentração em determinados tipos de interface e passa a haver uma adoção tendente ao equilíbrio entre os diversos tipos de mecanismos.
} 
tipo de interface no estoque global. Por outro, percebe-se crescimento da parcela das interfaces de caráter mais institucionalizado ou de inclusão coletivizada, como os conselhos, as audiências e as consultas públicas - passando de 27\%, em 2002, para $45 \%$, em 2010 (sem computar as conferências) ${ }^{5}$.

\section{Gráfico 3}

Percentual de interfaces socioestatais por tipo e ano

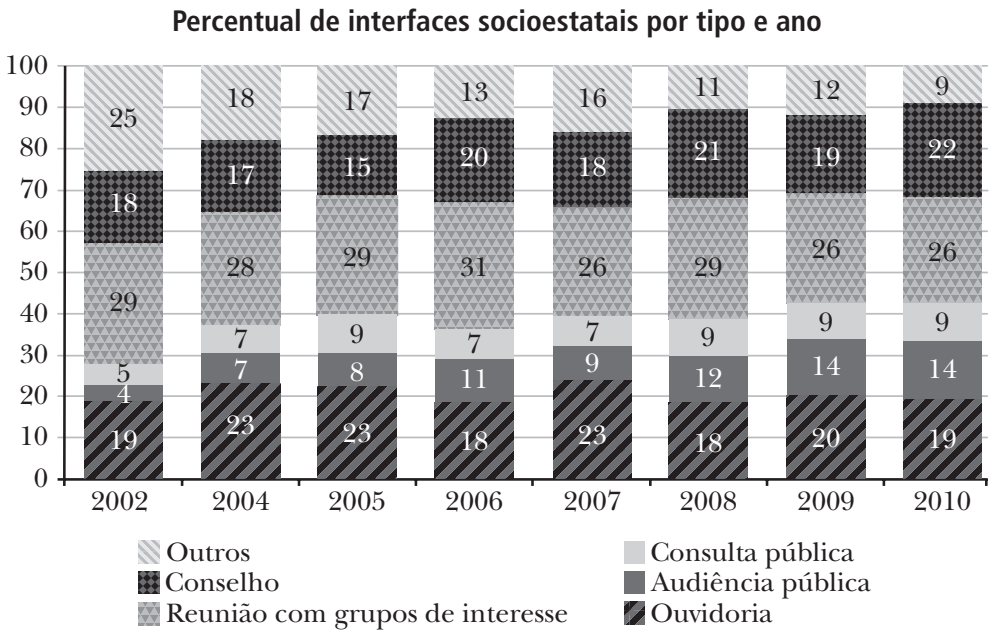

\begin{tabular}{|c|c|c|c|c|c|c|c|c|c|}
\hline & 2002 & 2004 & 2005 & 2006 & 2007 & 2008 & 2009 & 2010 & Geral $^{\text {***** }}$ \\
\hline Chi2(5) & 32,5 & 20,78 & 18,87 & 21,73 & 17,7 & 18,9 & 12,4 & 11,2 & 13,8 \\
\hline Pr & $0,0000^{\text {**** }}$ & $0,0008^{* * * *}$ & $0,0020^{\text {***** }}$ & $0,0005^{\text {***** }}$ & $0,0033^{\text {**** }}$ & $0,0019^{\text {***** }}$ & $0,0296^{* * *}$ & $0,0388^{* *}$ & $0,0492^{* * *}$ \\
\hline
\end{tabular}

Fonte: Elaboração própria com base em dados do Sigplan (2010).

\section{Distribuição das formas de interface socioestatal por área temática}

As informações analisadas até agora sugerem que há não apenas um incremento na adoção de formatos institucionais de interação, mas, também, uma diversificação dos tipos adotados. Todavia, para além dessa visão geral de inci-

\footnotetext{
5 Os dados sobre conferências não foram incluídos neste gráfico, pois estão disponíveis apenas para os anos 2009 e 2010.
} 
dência longitudinal das interfaces, vale questionar se existe algum padrão de distribuição temática ou setorial. Em face da variedade de estruturas de interfaces que vem sendo estabelecida, será que há algum padrão de concentração (ou dispersão) de tipos específicos de interface conforme os programas, órgãos ou setores da burocracia estatal?

Primeiro, estabelecemos uma classificação por áreas temáticas dos programas do governo federal, com base nas principais características descritivas dos programas, gerando quatro categorias. O Quadro 2 indica que na classe temática de Proteção e Promoção Social foi possível categorizar 35,1\% dos programas (percentual ligeiramente maior do que o caso dos programas da área de Infraestrutura, com 32,5\%). Ao categorizarmos as classes de Meio Ambiente e Desenvolvimento Econômico, encontramos valores também semelhantes entre si, com $16,3 \%$ e $16,1 \%$, respectivamente.

\section{Quadro 2}

Características das classes temáticas estruturadas

\begin{tabular}{|c|c|l|c|}
\hline Classe temática & Sigla & \multicolumn{1}{|c|}{ Descrição } & $\begin{array}{c}\% \text { de } \\
\text { Progs. }\end{array}$ \\
\hline $\begin{array}{c}\text { Proteção e } \\
\text { Promoção Social }\end{array}$ & PS & $\begin{array}{l}\text { Políticas sociais típicas (educação, saúde e } \\
\text { assistência) e serviços, projetos e ações para } \\
\text { promoção e garantia de direitos, proteção de } \\
\text { minorias etc. }\end{array}$ & 35,1 \\
\hline $\begin{array}{c}\text { Desenvolvimento } \\
\text { Econômico }\end{array}$ & DE & $\begin{array}{l}\text { Programas que desenvolvem ações de apoio, } \\
\text { fomento, regulação e financiamento, entre } \\
\text { outras, voltadas à promoção do desenvolvimento } \\
\text { econômico, ao setor produtivo, à organização do } \\
\text { mercado e ao estímulo ao crescimento econômico. }\end{array}$ & 16,1 \\
\hline Infraestrutura & IF & $\begin{array}{l}\text { Programas que incluem ações voltadas para o } \\
\text { desenvolvimento de infraestruturas nas diversas } \\
\text { áreas - seja logística e infraestrutura produtiva, } \\
\text { estrutura e qualidade dos serviços públicos, } \\
\text { infraestrutura urbana e urbanização, transporte, } \\
\text { energia, telecomunicações etc. }\end{array}$ & 32,5 \\
\hline $\begin{array}{l}\text { Meio Ambiente e } \\
\text { Recursos Naturais }\end{array}$ & MA & $\begin{array}{l}\text { Programas envolvendo iniciativas de prevenção } \\
\text { e conservação de recursos naturais - envolvendo } \\
\text { pesquisa, regulação, unidades de preservação etc. }\end{array}$ & 16,3 \\
\hline
\end{tabular}

Fonte: Elaboração própria com base em dados do Sigplan (2010). 
Os dados informados na Tabela 2 parecem já sugerir alguns padrões de variação entre as áreas de política pública. Se considerarmos, por exemplo, o caso da classe de Proteção e Promoção Social, fica evidente, em primeiro lugar, que se trata do conjunto de programas mais porosos à sociedade por mobilizar quase todas as modalidades de interface com maior frequência que os programas de outras áreas; e, em segundo lugar, que mobilizam com maior intensidade relativa interfaces como conselhos e conferências. A seu turno, quando verificamos essas mesmas interfaces para o caso da classe temática de Infraestrutura, por exemplo, constatamos percentuais significativamente menores. Nessa área, os programas tendem a concentrar interfaces menos frequentes na área da proteção social, como audiência pública e consulta pública.

\section{Tabela 2}

Percentual de classes temáticas por interface socioestatal

\begin{tabular}{|c|c|c|c|c|c|c|c|}
\hline & 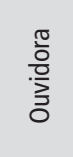 & 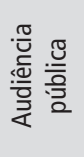 & 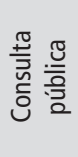 & 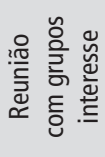 & 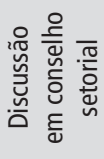 & 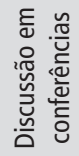 & 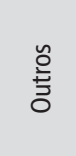 \\
\hline Infraestrutura & 37,6 & 42,8 & 33,0 & 26,4 & 19,9 & 11,9 & 23,9 \\
\hline $\begin{array}{c}\text { Desenvolvimento } \\
\text { Econômico }\end{array}$ & 17,4 & 10,1 & 15,9 & 15,2 & 12,1 & 19,0 & 20,7 \\
\hline $\begin{array}{c}\text { Proteção e } \\
\text { Promoção Social }\end{array}$ & 36,5 & 31,5 & 30,8 & 33,9 & 24,5 & 52,4 & 37,5 \\
\hline Meio Ambiente & 8,4 & 15,6 & 20,3 & 24,5 & 17,1 & 16,7 & 17,9 \\
\hline Total & 100,0 & 100,0 & 100,0 & 100,0 & 100,0 & 100,0 & 100,0 \\
\hline
\end{tabular}

$\mathrm{Chi}^{2}(18) \quad 148,81 * * * *$ Sig a NC $90 \% \backslash * *$ Sig a NC $95 \% \backslash * * *$ Sig a NC $99 \%$

Fonte: Elaboração própria com base em dados do Sigplan (2010).

Para verificar com maior acuidade os padrões encontrados na Tabela 2, fizemos uma análise de correspondên- 
cia $^{6}$ para testar estatisticamente e verificar graficamente a distribuição das interfaces socioestatais e sua relação com áreas de políticas públicas (classes temáticas de programas federais).

\section{Gráfico 4}

Plano espacial de associação: classes temáticas e interfaces socioestatais

\begin{tabular}{|c|c|c|c|}
\hline \multirow{6}{*}{ DE } & \multirow{6}{*}{$\mathrm{cp}$} & \multirow{6}{*}{ ap } & cs - conselhos \\
\hline & & & cf - conferências \\
\hline & & & ap - audiências públicas \\
\hline & & & сp - consultas públicas \\
\hline & & & ov - ouvidorias \\
\hline & & & rg - reuniões com grupos de interesse \\
\hline \multirow{6}{*}{$\mathrm{cs} \mathrm{cf}^{\mathrm{PS}}$} & \multirow[t]{6}{*}{ MA } & \multirow{6}{*}{ ov } & ot - outros \\
\hline & & & $\begin{array}{l}\text { ÁREAS DE POLÍTICAS PÚBLICAS } \\
\text { (CLASSES TEMÁTICAS) }\end{array}$ \\
\hline & & & DE - desenvolvimento econômico \\
\hline & & & PS - proteção e promoção social \\
\hline & & & IF - infraestrutura \\
\hline & & & $\begin{array}{l}\text { MA - meio ambiente e recursos } \\
\text { naturais }\end{array}$ \\
\hline
\end{tabular}

Fonte: Elaboração própria com base em dados do Sigplan (2010).

O Gráfico 4 apresenta os resultados da análise de correspondência. Quanto mais próximos os elementos dessas duas categoriais se apresentam no gráfico, maior é a associação observada - isto é, maior é a probabilidade de interfaces de um determinado tipo serem mobilizadas na gestão de programas federais de uma dada área temática.

${ }^{6}$ A análise de correspondência é uma técnica que estabelece correlação entre variáveis categóricas de uma tabela de contingência, objetivando verificar o grau de associação global, isto é, geral, entre os casos amostrais com base num plano tabular único (Triola, 2010). Neste caso, estamos usando a técnica de Análise de Correspondência Múltipla (ACM), a qual, diferentemente da técnica de Análise de Correspondência Simples (ACS), que estabelece correlação entre duas variáveis, consegue correlacionar diversas variáveis de uma só vez. 
Como pode ser observado no Gráfico 4, há relação de proximidade, estatisticamente testada ${ }^{7}$, entre a interface socioestatal reunião com grupos de interesse ( $\mathrm{rg}$ ) e a classe temática Desenvolvimento Econômico (DE), no quadrante superior esquerdo. Já as interfaces socioestatais consulta pública (cp) e audiência pública (ap) apresentaram proximidade, também estatisticamente significativa, à classe temática de Infraestrutura (IF), no quadrante superior direito. Em seguida, no quadrante inferior esquerdo, observa-se proximidade entre as interfaces conselhos (cs) e conferências (cf) e a classe temática de Proteção e Promoção Social (PS). Por último, no quadrante inferior direito, observa-se a presença da interface socioestatal ouvidoria (ov) e da área de Meio Ambiente. No entanto, esta classe temática apresentou proximidades quase equivalentes com outras interfaces como consulta pública, audiência pública e outros (ot). Assim, a área de Meio Ambiente, dada sua 80 proximidade ao centro do gráfico, não exibe um padrão claro de relação com alguma(s) interface(s) em específico. De forma semelhante, a categoria de interfaces outros também não apresenta relação clara com nenhuma classe temática, o que pode sugerir que interfaces desse tipo estão presentes em todas as áreas de políticas públicas. Por fim, apesar de não serem exibidas em um mesmo quadrante, percebe-se também proximidades relevantes entre a interface ouvidoria e a área temática de Infraestrutura.

Em síntese, se considerarmos apenas as classes temáticas dos programas, a análise feita gera evidências suficientes para afirmar que a determinados tipos de programa tendem a corresponder determinados tipos de interface socioestatal.

\footnotetext{
7 A tabela com as coordenadas específicas, e respectivos coeficientes, calculados para as variáveis encontra-se à disposição por meio de solicitação direta aos autores. A dimensão 1, horizontal, vale dizer, explicou $67,8 \%$ da variância total; a dimensão 2 , vertical, $32,2 \%$.
} 


\section{Interfaces socioestatais e suas contribuições para a gestão dos programas}

Esta seção lida com informações relativas à percepção dos gestores (os gerentes de cada programa federal) no tocante à avaliação dos efeitos e à importância das interfaces para a gestão e os resultados dos programas. Nos relatórios anuais de avaliação dos programas, os gerentes foram indagados sobre: "Quais foram as contribuições da participação para os resultados do programa?". Os gestores puderam respondê-la livremente, redigindo pequenos textos que revelavam suas opiniões. No total, foram obtidas 1.370 respostas, distribuídas entre os anos de 2004 e 2008, o que, considerando só esse período, bem como apenas o universo de programas nos quais a participação social é incentivada, perfaz aproximadamente $98 \%$ de respostas válidas.

Assim, essas respostas textuais foram submetidas a uma análise qualitativa que visou à identificação de padrões de argumentos dos atores diretamente associados à gestão dos programas. Depois da leitura e da sistematização das respostas três padrões de afirmação emergiram. Em primeiro lugar, o padrão "transparência e legitimidade" conforma os argumentos que definem a participação social como incentivadora de maior transparência e abertura nas ações desenvolvidas pelo governo, especialmente pela garantia da existência de regras decisórias e de inclusão mais claras. Logo em seguida, temos o grupo "correção de rumos e metodologias de ação", que congrega argumentos muito mais ligados à importância da participação como norteadora das ações a serem empreendidas pelo

\footnotetext{
8 Os relatórios anuais de avaliação dos programas estabeleciam um vínculo entre o termo "participação" e os sete tipos de interface que estão sendo trabalhados nesta análise (conselho, conferência, audiência pública, consulta pública, ouvidoria, reunião grupos de interesse, e outros). Assim, ao responder a questão exibida acima, podemos pressupor que os gestores levaram em consideração todas estas possibilidades e suas implicações para os resultados dos programas por eles coordenados.
} 
governo, especialmente no tocante aos processos de planejamento e desenho de estratégias de intervenção. Por último, temos o conjunto "fiscalização e controle", mais ligado aos argumentos de gestores que percebem a participação como instrumento efetivo de monitoramento, avaliação e controle das ações do governo. Nessas narrativas, a participação tem um caráter muito menos propositivo e muito mais reativo.

Ao entrecruzarmos as informações sobre os três tipos de argumento a respeito da contribuição das interfaces socioestatais na gestão dos programas com a classificação desses em quatro áreas temáticas, encontramos resultados interessantes (Tabela 3). Primeiro, os gestores dos programas da área de Proteção Social percebem que as interfaces socioestatais empregadas geram resultados mais perceptíveis nos campos de "transparência e legitimidade" e de "fiscalização e controle", ambos com, res82 pectivamente, $42 \%$ e $36 \%$, do que no campo da "correção de rumos e metodologias de ação”. Isso quer dizer que, na percepção dos gestores, há uma contribuição muito visível de controle por parte da sociedade civil, mas uma contribuição relativamente menor em termos de sugestões e indicações de rumos das ações.

Tabela 3

Percentual ponderado de incidência de interfaces por grupo temático

\begin{tabular}{|c|c|c|c|c|}
\cline { 2 - 5 } \multicolumn{1}{c|}{} & $\begin{array}{c}\text { Proteção } \\
\text { Social }\end{array}$ & $\begin{array}{c}\text { Meio } \\
\text { Ambiente }\end{array}$ & $\begin{array}{c}\text { Desenvolvimento } \\
\text { Econômico }\end{array}$ & Infraestrutura \\
\hline $\begin{array}{c}\text { Transparência e } \\
\text { legitimidade }\end{array}$ & 42 & 38 & 32 & 27 \\
\hline $\begin{array}{c}\text { Correção de rumos e } \\
\text { metodologias de ação }\end{array}$ & 22 & 29 & 43 & 45 \\
\hline Fiscalização e controle & 36 & 33 & 25 & 28 \\
\hline Total & 100 & 100 & 100 & 100 \\
\hline
\end{tabular}

Fonte: Elaboração própria com base em dados do Sigplan (2010). 
Em segundo lugar, ao olharmos o eixo de Meio Ambiente, observamos que as contribuições de "transparência e legitimidade" e "fiscalização e controle" caem para, respectivamente, $38 \%$ e $33 \%$, ao passo que aquele relativo à correção de rumos sobe para 29\%. Em comparação com o eixo de Políticas Sociais, a participação social no campo de Meio Ambiente tende a ter um caráter ligeiramente mais propositivo e menos fiscalizador. Em terceiro lugar, observamos maior diferenciação no que diz respeito aos programas da área de Desenvolvimento Econômico. A percepção dos gestores nessa área é de que as interfaces têm menor papel de "fiscalização e controle", com apenas $25 \%$ de casos. Nessa mesma linha, o percentual também é relativamente menor no que tange aos argumentos de "transparência e legitimidade", com 32\%. Sobressai, assim, com $43 \%$, a percepção de que a participação tem efeitos de sugestão para "correção de rumos e metodologias de ação" aventadas. Por fim, com relação aos programas da área de Infraestrutura, destaca-se o caráter sugestivo da participação, com um percentual de $45 \%$ para o grupo de "correção de rumos e metodologias de ação”, sendo as contribuições de "fiscalização e controle" e "transparência e legitimidade" percebidas com menor incidência, respectivamente, $28 \%$ e $27 \%$.

Para além da associação entre áreas temáticas de políticas e os argumentos de contribuição das interfaces para a gestão dos programas, tal como percebidos pelos seus gerentes, buscamos avaliar também como interfaces socioestatais podem estar associadas às distintas funções ou formas de contribuição. Para abordar essa questão, analisamos em cada programa federal os argumentos de contribuição apresentados por seus gerentes e identificamos quais interfaces compareciam a elas associadas. Como forma de testar essas aproximações, procedemos a uma análise de correspondência. O Gráfico 5 ilustra os resultados, localizando espacialmente as proximidades entre tipos de interface e suas contribuições, na percepção dos gestores envolvidos. 


\section{Gráfico 5}

Plano espacial de associação: interfaces e argumentos de contribuição

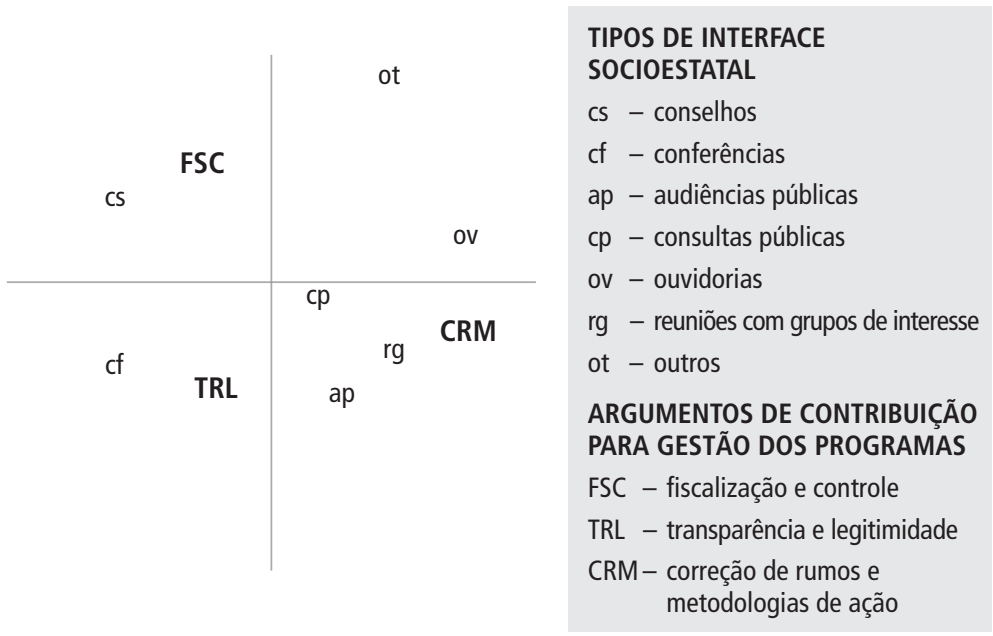

Fonte: Elaboração própria com base em dados do Sigplan (2010).

Podemos observar que há maior associação entre interfaces como conselhos e contribuições de fiscalização e controle (quadrante superior esquerdo), entre conferências e contribuições de transparência e legitimidade (quadrante inferior esquerdo), e entre interfaces como audiências públicas, consultas públicas e reuniões com grupos de interesse e contribuições de correção de rumos e metodologia de programas (quadrante inferior direito). Já as ouvidorias (quadrante superior direto) também apresentam proximidade à contribuição de correção de rumos. A posição da categoria outros, por sua vez, sugere que potencialmente tenha associações com todas as contribuições possíveis, não apresentando ligações fortes com nenhuma das categorias de contribuição em específico.

Esses resultados sugerem que tipos de interface não apenas estão associados às áreas de políticas (como visto, por exemplo, no caso das conferências e dos conselhos e a área 
de Políticas Sociais, no Gráfico 4), mas também estão associados a tipos distintos de contribuições percebidas pelos gestores (fiscalização/controle, legitimidade/transparência, e correção de rumos). Tais associações indicam, portanto, que, pelo menos nesta última década, os diferentes tipos de interface socioestatal têm sido percebidos pelos gestores como processos promotores de funções específicas e não genéricas. Por exemplo, as conferências não têm sido percebidas pelos gestores como elementos que contribuem para o controle ou para a discussão de alterações em projetos de intervenções específicas (como obras de infraestrutura), mas, sim, para a transparência e a legitimidade das ações governamentais. Da mesma forma, os gestores percebem que as audiências públicas têm proporcionado benefícios ao gerar debate em torno de projetos e ações pontuais, mas não para a discussão de diretrizes gerais para o planejamento das políticas a médio e longo prazos. Finalmente, os conselhos têm sido vistos por estes atores como estimuladores de fiscalização e controle, função que provavelmente interfaces como conferências e audiências não seriam capazes de exercer de forma continuada e sistemática.

Este estudo se dedicou a um mapeamento analítico das variadas formas de interação entre Estado e sociedade no Brasil contemporâneo, levantando informações não apenas sobre a evolução e incidência de interfaces socioestatais nos programas federais, mas também sobre sua relação com as diferentes áreas do governo e com os variados papéis e contribuições que podem vir a desempenhar. $\mathrm{O}$ conjunto de dados analisados pode ser sintetizado em quatro principais conclusões:

1. Em primeiro lugar, percebeu-se um crescimento relevante em termos do número de interfaces socioestatais nos programas e órgãos do governo federal. Nota-se incremento consistente ao 
longo da década na adoção de formas de interação, chegando a quase $90 \%$ dos programas com pelo menos algum tipo de interface socioestatal. Esse aumento ao longo do tempo foi observado tanto no que diz respeito à adoção de interfaces por órgãos que antes não a praticavam, como também pelo incremento nos programas de órgãos que desde o início da década já incentivavam formas de interação com a sociedade.

2. Em segundo, tornou-se bastante visível a consolidação de uma diversificação dos formatos de interface socioestatal que se consolidaram na última década, envolvendo ouvidorias, reuniões com grupos de interesse (como as mesas de diálogo, comitês diversos e outras experiências mais pontuais), audiências públicas, consultas públicas, conselhos, conferências e outros (envolvendo sítios de internet, ações de transparência e atendimento ao cidadão etc.)

3. Em terceiro lugar, observou-se certo padrão de associação entre tipos de interface socioestatal e áreas temáticas de políticas públicas. Enquanto interfaces como conselhos e conferências apresentaram maior vínculo relativo aos programas da área de Proteção e Promoção Social, audiências e consultas públicas e reuniões com grupos de interesse se apresentaram mais associadas às temáticas de Infraestrutura e Desenvolvimento Econômico, respectivamente.

4. Por fim, a quarta conclusão possível diz respeito à percepção dos gestores sobre a contribuição das interfaces para a gestão dos programas. Ao passo que nas áreas Social e de Meio Ambiente, gestores perceberam as interfaces socioestatais como importantes para a garantia de transparência e legitimidade das ações e para a fiscalização e o controle dos programas, nas áreas de Desenvolvimento Econômico e Infraestrutura prevaleceu o papel de correção de rumos e metodologias dos programas. Detectou-se também que essa percepção sobre os papéis e as contribuições alinhava-se com tipos específicos de interface. Enquanto conselhos e conferências apresentavam-se associados ao aumento de legitimidade, à transparência 
e ao controle, audiências e consultas públicas, assim como as reuniões com grupos de interesse, demonstraram maior aproximação com a função de correção de rumos e metodologias dos programas.

As constatações deste mapeamento permitem uma interpretação renovada e mais ampla sobre a evolução e a consolidação das relações Estado-sociedade no Brasil nas últimas décadas. Se, por um lado, é verdade que formas de participação social, como conselhos e conferências, as quais têm recebido bastante atenção pública e acadêmica, se disseminaram e adquiriram crescente importância na gestão dos programas federais, por outro, outras formas de interação, como ouvidorias, audiências e consultas públicas, reuniões, comitês, grupos de trabalho e portais de internet, entre outros, se mostraram igualmente presentes e relevantes, muito embora ainda não tenham recebido a devida atenção analítica e raramente sejam considerados nas análises sobre a democratização do Estado brasileiro.

Assim, os resultados da pesquisa chamam atenção para a necessidade de pensarmos as interações entre Estado e sociedade no Brasil com lentes analíticas mais abrangentes, que permitam não só a percepção de uma variedade maior de possibilidades formais de contato, mas também um entendimento sobre as relações entre esses. As evidências fornecidas pelo mapeamento sustentam a visão de uma "ecologia" das relações Estado-sociedade, que vem se conformando gradualmente no Brasil. A ideia de ecologia remete à percepção de um sistema complexo, composto por partes/unidades diferenciáveis (tipos) que tendem a desempenhar funções específicas (papéis) e naturalmente se associar às estruturas e aos ambientes (áreas temáticas) nas quais sua contribuição faça sentido e seja necessária. Assim, nessa ecologia das relações Estado-sociedade, diferentes interfaces viabilizam o contato entre Estado e sociedade em diferentes políticas públicas para o cumprimento de diferentes objetivos. 
Tal perspectiva abre uma série de questionamentos relevantes. Por um lado, a percepção da ecologia sugere a relevância da multiplicidade de pontos de acesso ao Estado em face da diversidade de atores sociais existentes, promovendo a ampliação das interações do Estado com setores distintos da sociedade (sejam atores coletivos, privados, individuais, organizados e não organizados, de forma presencial ou não presencial etc.). Por outro, levanta inquietações sobre as origens desse processo e as possíveis explicações para a emergência e a persistência de uma variedade de interfaces.

Argumentamos que tentativas de explicação desse fenômeno requerem uma abordagem relacional. Uma possível hipótese sugere que a variedade de interfaces socioestatais e sua distribuição temática e setorial estão associadas aos padrões de relacionamento entre atores sociais e burocracia nas diferentes áreas de atuação do Estado. A adoção ou o desenvolvimento de um tipo de interface socioestatal 88 resultaria do perfil dos atores sociais envolvidos e das formas de relação com a burocracia responsável por uma política específica. Esse padrão de relacionamento seria então responsável pela construção nas burocracias, ao longo do tempo, de vocações, habilidades e repertórios próprios para se relacionar com a sociedade. Isto é, enquanto algumas áreas da burocracia apresentam uma trajetória mais longa de relação com movimentos sociais e atores coletivos e tendem a estabelecer com eles interfaces coletivizadas, públicas e de participação social ampla; em outras áreas, um histórico de relações entre a burocracia e atores privados ou não organizados pode levar à conformação de interfaces mais restritas e seletivas. Em suma, o tipo de ator social (forma de organização, projetos políticos etc.) e os padrões históricos de relação entre ele e a burocracia podem explicar o desenvolvimento de repertórios burocráticos de interação e a constituição e manutenção de uma variedade de interfaces socioestatais. 
A noção de repertório burocrático de interação pode ser bastante útil para explicar não só a adoção de diferentes tipos de interface, mas também as variações no desempenho dos mecanismos de interação. Isto é, o sucesso ou a efetividade de interfaces socioestatais, no que tange à sua capacidade de influenciar políticas públicas e ações de governo, pode ser fruto também desses distintos repertórios burocráticos. Além disso, reconhecer tais repertórios pode ser importante para identificar os tipos de interface socioestatais adequados para cada organização do Estado ou para prever os resultados de seu funcionamento.

Certamente, esta abordagem não esgota outras possibilidades de explicação para o fenômeno, as quais poderiam derivar da natureza ou do tipo das políticas públicas (seja pelo seu conteúdo substantivo, seja pelo seu caráter distributivo, redistributivo, regulatório etc.), do perfil dos atores técnicos e políticos que ocupam a burocracia estatal (quer na sua direção, quer na implementação das ações), além das normas e dos regulamentos que organizam a atuação do Estado em cada setor. Todas essas possibilidades de explicação ainda demandam desenvolvimento teórico e testes empíricos, mas sugerem que pensar as relações entre Estado e sociedade no Brasil da perspectiva das interfaces socioestatais abre novos caminhos para pesquisas sobre o tema.

\section{Roberto R. C. Pires}

é doutor em Políticas Públicas pelo Massachusetts Institute of Technology (MIT) e técnico de Pesquisa e Planejamento do Instituto de Pesquisa Econômica Aplicada (IPEA).

\section{Alexander C. N. Vaz}

é doutor em Ciência Política pela Universidade Federal de Minas Gerais (UFMG). 


\section{Bibliografia}

AVELAR, L. 2007. "Participação política". In: AVELAR, L.; CINTRA,

A. (orgs.) Sistema político brasileiro: uma introdução. Rio de Janeiro:

Fundação Konrad Adenauer-Stiftung; São Paulo: Fundação Unesp.

AVRITZER, L. 1994. Sociedade civil e democratização. Belo Horizonte: Del

Rey.

2002. Democracy and the public space in Latin America. Princeton:

Princeton University Press.

2012. Conferências nacionais: ampliando e redefinindo os padrões

de participação social no Brasil. Rio de Janeiro: Ipea. (Texto para

Discussão, n. 1739).

COHEN, J.; ARATO, A. 1994. Civil society and political theory. Cambridge

MA: MIT Press.

DAGNINO, E. 2002. "Sociedade civil e espaços públicos no Brasil”. In:

DAGNINO, E. (org.). Sociedade civil e espaços públicos no Brasil. São

Paulo: Paz e Terra, pp. 9-15.

HABERMAS, J. 1996. Between facts and norms. London: Polity Press.

HEVIA, F; VERA, E. 2010. "La perspectiva de interfaz aplicada a las relaciones sociedad civil-Estado en México”. In: OLVERA, A. (org.).

La democratización frustrada: limitaciones institucionales y colonización política de las instituciones garantes de derechos y de participación ciudadana en México. Ciudad de México: Ciesas, Universidad Veracruzana.

IBGE. 2009. Perfil dos Municípios Brasileiros 2009 (MUNIC).

Disponível em: <http://www.ibge.gov. br/home/estatistica/ economia/perfilmunic/2009/defaulttabzip.shtm7>. Acesso em: 27 dez. 2014.

LAVALLE, A.; VERA, E. 2010. "Precisiones conceptuales para el debate contemporáneo sobre la innovación democrática: participación, controles sociales y representación”. In: LAVALLE, A.; VERA, E. (orgs.). La innovación democrática en América Latina. Tramas y nudos de la representación, la participación y el control social. Ciudad de México: Ciesas, Universidad Veracruzana.

LONG, N. 1999. "The multiple optic of interface analysis". Unesco Background Paper on Interface Analysis, Oct. . 2004. "Actors, interfaces and development intervention: meaning, purposes and powers". In: KONTINEN, T. (org.). Development intervention: actor and activity perspectives. Helsinki: University of Helsinki. Center for Activity Theory and Developmental Work Research and Institute for Development Studies, pp. 14-36. 
PIRES, R.; LOPEZ, F. 2010. "Instituições participativas e políticas públicas no Brasil: características e evolução nas últimas décadas”. In: Ipea. Brasil em desenvolvimento 2010: Estado, planejamento e políticas públicas. Brasília: Ipea, pp. 565-88.

PIRES, R.; VAZ, A. 2012. Participação social como método de governo? Um mapeamento das "interfaces sociestatais" nos programas federais. Brasília: Ipea. (Texto para Discussão, n. 1707).

ROBERTS, B. 2001. "The new social policies in Latin America and the development of citizenship: an interface perspective". Paper for Workshop on Agency, Knowledge and Power: New Directions. Wageningen, pp. 14-15, Dec.

SANTOS, B.; AVRITZER, L. 2002. "Para ampliar o cânone democrático". In: SANTOS, B. (org.). Democratizar a democracia. Rio de Janeiro: Civilização Brasileira.

SIGPLAN - Sistema de Informações Gerenciais e de Planejamento. Módulo de avaliação dos PPAs de 2002 a 2010. Ministério do Planejamento, Orçamento e Gestão (MPOG). Disponível em: <www.siop.planejamento.gov.br>. Acesso em: 27 dez. 2014.

TRIOLA, M. 2010. Elementary statistics. London: Pearson Education.

VERA, E. 2006. "Interfaces socioestatais, prestação de contas e projetos políticos no contexto da transição política mexicana”. In: DAGNINO, E.; OLVERA, A.; PANFICHI, A. (orgs.). A disputa pela construção democrática na América Latina. São Paulo: Paz e Terra.

VERA, E.; HEVIA, F. 2006. "Relaciones sociedad civil-Estado en México: un ensayo de interpretación”. Cuadernos para la democratización, Xalapa, Ciesas, n. 4.

VERA, E.; LAVALLE, A. 2012. "Arquitetura da participação e controles democráticos no Brasil e no México”, Novos Estudos Cebrap, n. 92, pp. 105-21, mar. 


\section{PARA ALÉM DA PARTICIPAÇÃO: INTERFACES SOCIOESTATAIS NO GOVERNO FEDERAL}

ROBERTO R. C. PIRES

ALEXANDER C. N. VAZ

Resumo: O estudo procura fazer um mapeamento analítico das atuais formas de interação entre atores estatais e sociais nos processos de formulação e controle de políticas públicas no Brasil. Para tal, adota o conceito de interfaces socioestatais com o objetivo ampliar nossa capacidade de compreender o fenômeno, indo além das abordagens que enfatizaram apenas os espaços de participação e deliberação. As análises envolvem dados sobre todos os programas federais de 2002 a 2010, indicando os padrões de evolução temporal, diversificação e distribuição setorial de interfaces socioestatais em nível nacional. Os resultados revelam que as diferentes interfaces socioestatais têm afinidades com diferentes setores da burocracia federal, desempenhando neles papéis também diferenciados, sustentando a percepção de uma "ecologia" complexa das relações entre Estado e sociedade no Brasil contemporâneo.

Palavras-chave: Políticas Públicas; Burocracia; Participação; Interfaces Socioestatais

\section{BEYOND PUBLIC PARTICIPATION: INTERFACES IN THE BRAZILIAN FEDERAL GOVERNMENT}

Abstract: The paper develops an analytical mapping of contemporary forms of interaction between state and societal actors in the processes of making and controlling public policies in Brazil. In order to broaden the scope of analysis and go beyond current approaches that have emphasized participation spaces and public deliberation, we use the concept "state-society interfaces". We analyze data on all federal programs from 2002 to 2010, trying to identify the patterns 
of longitudinal evolution, diversification, and sectorial distribution of a set of interfaces at the national level. The findings reveal that different types of state-society interfaces are associated with different sectors of the federal bureaucracy, performing different roles in each of them. We argue these findings support the perception of a complex "ecology" of state and society relationship in contemporary Brazil. Keywords: Public Policy; Bureaucracy; Participation; Interfaces 